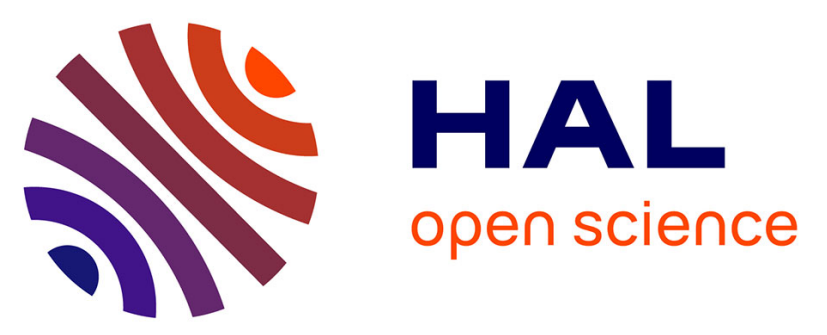

\title{
MULTI-PHYSICS DESIGN RULES USING LUMPED MODELS FOR A PERMANENT MAGNET SYNCHRONOUS MACHINE
}

Nicolas Bracikowski, Mathieu Rossi, Michel Hecquet, Frederic Gillon, Pascal Brochet

\section{To cite this version:}

Nicolas Bracikowski, Mathieu Rossi, Michel Hecquet, Frederic Gillon, Pascal Brochet. MULTIPHYSICS DESIGN RULES USING LUMPED MODELS FOR A PERMANENT MAGNET SYNCHRONOUS MACHINE. International Journal of Applied Electromagnetics and Mechanics, 2013. hal-01730149

\author{
HAL Id: hal-01730149 \\ https://hal.science/hal-01730149
}

Submitted on 13 Mar 2018

HAL is a multi-disciplinary open access archive for the deposit and dissemination of scientific research documents, whether they are published or not. The documents may come from teaching and research institutions in France or abroad, or from public or private research centers.
L'archive ouverte pluridisciplinaire HAL, est destinée au dépôt et à la diffusion de documents scientifiques de niveau recherche, publiés ou non, émanant des établissements d'enseignement et de recherche français ou étrangers, des laboratoires publics ou privés. 


\title{
MULTI-PHYSICS DESIGN RULES USING LUMPED MODELS FOR A PERMANENT MAGNET SYNCHRONOUS MACHINE
}

\author{
Nicolas BRACIKOWSKI, Mathieu ROSSI, Michel HECQUET, Fréderic GILLON, \\ Pascal BROCHET
}

\author{
University Lille Nord de France, L2EP, EC-Lille, F-59651 Villeneuve d'Ascq, France, \\ E-mail: nicolas.bracikowski@ec-lille.fr, michel.hecquet@ec-lille.fr
}

\begin{abstract}
Modeling the dynamic behavior of electrical machines involves several fields of physics, such as electromagnetics, electronics, mechanics, thermodynamics and acoustics. Multi-physics lumped models are applied to an inverter-fed permanent magnet synchronous machine. These models are coupled and fully parameterized to optimize the machine for traction applications. A particle swarm optimization algorithm is used to obtain general tendencies and different design rules. The objective is to provide a decision-making tool using lumped models to design permanent magnet synchronous motors. In this paper, we focus on electromagnetic noise, and average and ripple electromagnetic torque. The magnetic model, a permeance network, provides a good compromise between accuracy and computing time.
\end{abstract}

Keywords: Electromagnetic acoustic noise, Instantaneous electromagnetic torque Multi-physics lumped models, Particle swarm optimization, Permanent magnet machines.

\section{INTRODUCTION}

The physical system studied is a permanent magnet synchronous machine (PMSM). This PMSM is used for traction applications, which means that variable speed and high power are needed. The rated power of the machine is $250 \mathrm{KW}$ and it provides a torque of $960 \mathrm{Nm}$ at $2500 \mathrm{rpm}$.

Designers must therefore predict the machine behavior in terms of electromagnetic, thermal, mechanical and acoustic characteristics. Regarding the thermal sensitivity of the permanent magnets, it is known that PMSM must often be coupled with the thermal model. Moreover, although permanent magnet machines are considered to have low acoustic noise, it is difficult to assume that they are noiseless as different families of forces can act on the structure in variable speed applications [1], [2]. Acoustic comfort becomes crucial for certain applications such as electrical transport systems. A model of the power electronics is used to take into account different PWM strategies in order to estimate the effect of an inverter of audible magnetic noise.

Although well-known finite element analysis (FEA) tools can compute these different multi-physical motor characteristics, coupling them can be difficult and often prohibitive in terms of computational time, particularly in optimization processes. Lumped models offer a good compromise between analytical and finite element design tools, provide access to different local values and reduce computing time.

The first part of this article presents four different lumped models: electronic, electric, magnetic and two analytical ones: mechanical (torque) and vibro-acoustic (noise). The thermal model was described in [3]. Here, we place emphasis on mechanical and vibro-acoustic models. All the physical phenomena interact with each other, with weak or strong coupling [3].

In the second part, an optimization algorithm is used to identify an optimal set of points. A sub-swarm MOPSO (Multi-Objective Particle Swarm Optimization) implementation is used here with a dominance-based multi-objective strategy that divides the population of particles into several sub-swarms. The optimization objectives are to maximize the average torque and to minimize the electromagnetic noise while taking torque ripple into account. A sensitivity analysis of the solutions proposed by the Pareto front is used to complete the selection process by checking the robustness of the design of several points.

The electromagnetic results for different PWM strategies are validated by experimental measurements. The originality of this study is that it provides a pre-sizing tool, i.e. an optimization tool coupled with multiphysics lumped models of a PMSM that take into account local values and offer good computation time. This tool allows highlighting several rules for multi-physics electrical motor design that make it possible to reduce electromagnetic noise with different constraints such as electromagnetic torque versus speed. 


\section{MULTI-PHYSICS MODELS}

Different lumped models are defined for each physical domain. These topologies are chosen according to geometrical considerations and based on knowledge of the predominant direction of electrostatic, electrical, magnetic, vibratory (unidirectional compressed/stretched deflection) and thermal flux in the PMSM. The flux path is decomposed into elements in which we consider flux conservation. Each element is associated with a value (1) that expresses the capability of this element to withstand the circulation multi-physics fluxes in the PMSM (Tab.1) and provides the matrix form (Tab.2).

$$
D=\int_{0}^{l} \tau(x)^{-1} \times S(x)^{-1} \times d x
$$

With:

$\tau$ being the electrostatic, electrical, magnetic, thermal and vibratory conductivity of material;

$\mathrm{S}, 1$, the section and length of the flux tube considered.

Table 1. Some examples of a dipole estimated by (1) for various fields of physics.

\begin{tabular}{|c|c|c|c|c|}
\hline Electrostatic & Electric & Magnetic & Thermal & Vibratory \\
\hline \hline $\int_{0}^{1} \varepsilon(\mathrm{x})^{-1} \mathrm{~S}(\mathrm{x})^{-1} \mathrm{dx}$ & $\int_{0}^{1} \sigma(\mathrm{x})^{-1} \mathrm{~S}(\mathrm{x})^{-1} \mathrm{dx}$ & $\int_{0}^{1} \mu(\mathrm{x})^{-1} \mathrm{~S}(\mathrm{x})^{-1} \mathrm{dx}$ & $\int_{0}^{1} \lambda(\mathrm{x})^{-1} \mathrm{~S}(\mathrm{x})^{-1} \mathrm{dx}$ & $\int_{0}^{1} \mathrm{E}(\mathrm{x})^{-1} \mathrm{~S}(\mathrm{x})^{-1} \mathrm{dx}$ \\
\hline$\varepsilon:$ permittivity & $\sigma:$ elec. conductivity & $\mu:$ permeability & $\lambda:$ ther. conductivity & $\mathrm{E}$ : Young's modulus \\
\hline
\end{tabular}

Table 2. Some examples of matrix form for various fields of physics.

\begin{tabular}{|c|c|c|c|c|}
\hline Electrostatic & Electric & Magnetic & Thermal & Vibratory \\
\hline \hline$\{\mathrm{q}\}=\left[\mathrm{D}_{\mathrm{es}}\right]\{\mathrm{U}\}$ & $\{\mathrm{U}\}=\left[\mathrm{D}_{\mathrm{el}}\right]\{\mathrm{I}\}$ & $\{\varepsilon\}=\left[\mathrm{D}_{\mathrm{mg}}\right]\{\varphi\}$ & $\{\mathrm{T}\}=\left[\mathrm{D}_{\mathrm{th}}\right]\{\Phi\}$ & $\{\mathrm{X}\}=\left[\mathrm{D}_{\mathrm{vb}}\right]\{\mathrm{F}\}$ \\
\hline $\mathrm{q}:$ electric charge & $\mathrm{U}:$ voltage & $\begin{array}{c}\varepsilon: \text { magnetomotive } \\
\text { force }\end{array}$ & $\mathrm{T}:$ temperature & $\mathrm{X}$ : position \\
\hline $\mathrm{U}:$ voltage & $\mathrm{I}:$ current & $\varphi$ : magnetic flux & $\Phi:$ thermal flux & $\mathrm{F}$ : force \\
\hline
\end{tabular}

Parameterized networks were implemented to build these multi-physics models. These different systems are expressed in a matrix form with classical Kirchhoff laws, i.e. Kirchhoff's current law (2) for Fig.1a and Kirchhoff's voltage law (3) for Fig.1b. Here, 'V' expresses potentials, ' $F$ ' multi-physics voltage sources and ' $\varphi$ ' multi-physics fluxes in these circuits.

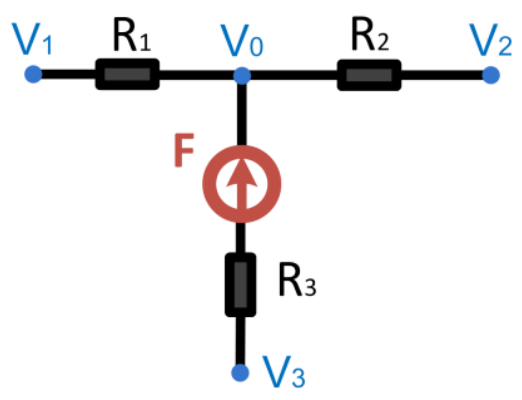

a/ First example

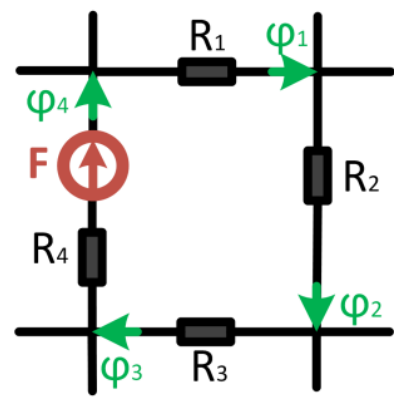

b/ Second example

Figure 1. Lumped models 


$$
\left\{\begin{array}{c}
F / R_{3} \\
0 \\
0 \\
0 \\
\ldots \\
\ldots
\end{array}\right\}=\left[\begin{array}{ccccccc}
-\sum_{k=1}^{3} \frac{1}{R_{k}} & \frac{1}{R_{1}} & \frac{1}{R_{2}} & \frac{1}{R_{3}} & 0 & \ldots & 0 \\
\ldots & \ldots & \ldots & \ldots & \ldots & \ldots & \ldots \\
\ldots & \ldots & \ldots & \ldots & \ldots & \ldots & \ldots \\
\ldots & \ldots & \ldots & \ldots & \ldots & \ldots & \ldots
\end{array}\right\}\left\{\begin{array}{c}
V_{0} \\
V_{1} \\
V_{2} \\
V_{3} \\
\ldots \\
\ldots
\end{array}\right\}
$$

$$
\left\{\begin{array}{c}
F \\
0 \\
0 \\
0 \\
\ldots
\end{array}\right\}=\left[\begin{array}{ccccccc}
R_{1} & R_{2} & R_{3} & R_{4} & 0 & \ldots & 0 \\
\ldots & \ldots & \ldots & \ldots & \ldots & \ldots & \ldots \\
\ldots & \ldots & \ldots & \ldots & \ldots & \ldots & \ldots \\
\ldots & \ldots & \ldots & \ldots & \ldots & \ldots & \ldots
\end{array}\right\}\left\{\begin{array}{c}
\varphi_{1} \\
\varphi_{2} \\
\varphi_{3} \\
\varphi_{4} \\
\ldots \\
\ldots
\end{array}\right\}
$$

Other elements such as inductors (for example, the leakage of fluxes back to the electrical circuit) and capacitors (for example, temperature transients) can be added. They provide dynamic models with differential equations. In our model, the electromagnetic models are expressed in (4) with the differential equations of the magnetic fluxes due to strong electromagnetic coupling (Ampere and Faraday laws) [4], and the thermal model is expressed in (5) with differential equations on temperatures (Fourier law) [5]. These systems of equations are solved using classical numerical methods. In both these cases, we chose to estimate the derivative using the Euler method, for the sake of simplicity. The matrix form and the resolution were carried out in the Matlab® environment.

$$
\begin{aligned}
& \{\varphi\}=[A]\{\varphi\}+\{b\} \\
& \{T\}=[A]\{T\}+\{b\}
\end{aligned}
$$

The electrical part uses classical circuits and is directly linked to the electronic model: the PWM inverter (Fig.2a). The magnetic circuit is modeled by a permeance network that takes into account saturation and movement (Fig.2b). The electromagnetic torque and electromagnetic noise have the same origins, given by the Maxwell forces. We decompose the electromagnetic force into two parts (6a and $6 \mathrm{~b}$ ).

$$
d F_{N} / d S=\left[B_{N}^{2}-B_{T}^{2}\right] / 2 \mu_{0}
$$

$$
d F_{T} / d S=\left[B_{N} \times B_{T}\right] / \mu_{0}
$$

With $\mathrm{B}_{\mathrm{N}}, \mathrm{B}_{\mathrm{T}}$ being the normal and tangential air-gap flux density components, respectively; $\mu_{0}$, the magnetic permeability of air.

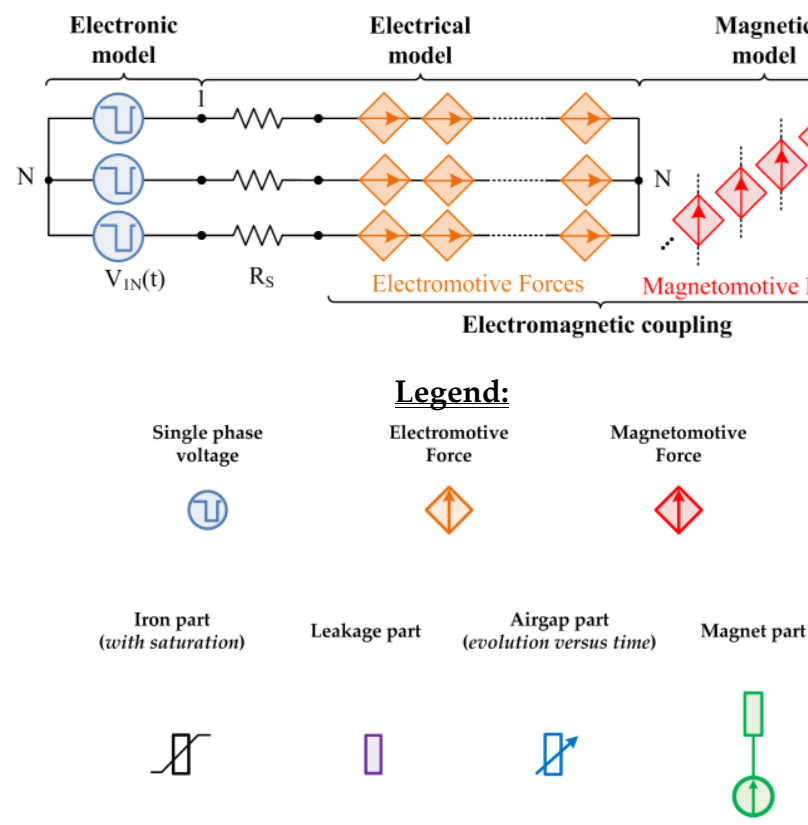

a/ Electical circuit with electronic sources

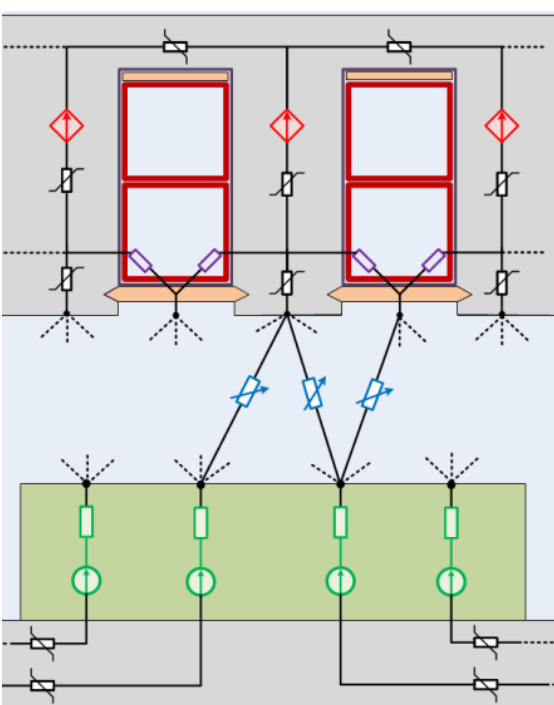

b/ Part of the magnetic circuit

Figure 2. Electronic-Electrical-Magnetic circuits 
We deduced the mechanical force by the co-energy variation (7a and 7b) [6] and not from Maxwell's stress tensor ( $6 \mathrm{a}$ and $6 \mathrm{~b}$ ). Indeed, our permeances network provides us only with information on the normal component of flux density in the air-gap (Fig.2). This allows a reduced number of branches in the network and therefore a faster model.

The instantaneous electromechanical torque of the machine is deduced using ( $7 \mathrm{~b})$ and not from Maxwell's stress tensor (6). The derivative of the permeance versus time is estimated by the Euler method. The electromagnetic torque fluctuates due to the teeth effect and flux density harmonics. These fluctuations are calculated using (8). [

$$
\begin{aligned}
& F_{R}(t, \theta)=-\frac{1}{2 \mu_{0} S} \sum_{u=0}^{U_{\max }} \sum_{v=0}^{V_{\max }} \varphi_{u, v}(t, \theta)^{2} \\
& F_{T}(t, \theta)=\frac{\Gamma_{e m}(t, \theta)}{r}=\frac{1}{r \Omega(t)} \sum_{u=0}^{U_{\max }} \sum_{v=0}^{V_{\max }} \frac{\Lambda_{u, v}(t, \theta)-\Lambda_{u, v}(t-\Delta t, \theta)}{\Delta t} \frac{\Delta \varepsilon_{u, v}(t, \theta)^{2}}{2}
\end{aligned}
$$

With:

B: air-gap flux density; r: average radius of the air-gap; $S$ : inner surface of the stator; $\Lambda$ : air-gap permeance; $\Delta \varepsilon$ : magnetomotive forces; $\theta$ : rotor position; $\Delta \mathrm{t}$ : simulation time step; $\mathrm{u}, \mathrm{v}$ : the index of the node at the boundary between the stator and the air-gap and the rotor and the air-gap, respectively; $\mathrm{U}_{\max }, \mathrm{V}_{\max }$ : the maximum number of nodes at the boundary between the stator and the air-gap and the rotor and the air-gap, respectively;

$$
\Gamma_{\text {ripple }}=\left\{\frac{\Gamma_{\text {max }}-\Gamma_{\min }}{2 \Gamma_{\text {average }}}\right\} \times 100
$$

To perform the vibration study, the stator will be treated as a simple geometric shape, in this case a cylinder. This assumption allows an analytical solution of the mechanical equations and thus permits a modal analysis. The vibration model is therefore regarded as a modal superposition of amortized mass-spring systems (9) and provides the following electrical analogy (10).

$$
\begin{aligned}
& K_{m} Y_{m}(t)+B_{m} \dot{Y}_{m}(t)+M_{m} \ddot{Y}_{m}(t)=F_{R_{m}}(t) \\
& \frac{1}{C} q(t)+R \dot{q}(t)+L \ddot{q}(t)=U(t)
\end{aligned}
$$

We can therefore associate a system composed of masses with our machine: ' $\mathrm{M}_{\mathrm{m}}$ ' ( $\mathrm{XX}$ and $\left.\mathrm{XX}\right)$ and springs ' $\mathrm{K}_{\mathrm{m}}$ ' ( $\mathrm{XX}$ and $\mathrm{XX}$ ) for each of the modes ' $\mathrm{m}$ ' [1]. The shock absorption ' $\mathrm{B}_{\mathrm{m}}$ ' (15) is obtained by the damping coefficient ' $\zeta_{\mathrm{m}}$ ', estimated by an empirical formulation (16) [2]. The modal deflection shape ' $\mathrm{Y}_{\mathrm{m}}$ ' results from the forced responses. These excitations stem from the radial forces that are decomposed with an FFT in the spatial domain ' $\mathrm{F}_{\mathrm{m}}(\mathrm{t})$ ' to make it compatible with the modal superposition.

For a compressed/stretched deflection with a mode shape equal zero $(\mathrm{m}=0)$ :

$$
\begin{aligned}
& M_{m=0}=\rho 2 \pi r_{c y} h_{c y} l_{c y} \\
& K_{m=0}=2 \pi E \frac{h_{c y}}{r_{c y}} l_{c y}
\end{aligned}
$$

For a bending mode with a mode shape higher than or equal to two $(\mathrm{m} \geq 2)$ :

$$
\begin{aligned}
& M_{m>1}=\rho 2 \pi r_{c y} h_{c y} l_{c y} \frac{m^{2}+1}{m^{2}} \\
& K_{m>1}=2 \pi \frac{l_{c y} h_{c y}{ }^{3}}{12} \frac{E}{r_{c y}{ }^{3}}\left(m^{2}-1\right)^{2}
\end{aligned}
$$


The dimensions of the cylinder are denoted ' $r_{c y}$ ' for the average radius, ' $h_{c y}$ ' for the thickness and ' $1_{c y}$ ' for the length. The characteristics of the material are denoted ' $E$ ' for the Young's modulus and ' $\rho$ ' for the mass density.

The shock absorption and damping coefficient for any mode are:

$B_{m}=\frac{K_{m} \zeta_{m}}{\pi f_{m}}$

$\zeta_{m}=\frac{2.75 \times 10^{-5} f_{m}+0.062}{2 \pi}$

Resonance phenomena may occur when there is a spatial coincidence between the spatial order (linked to the harmonic force) and the number of modes (linked to the natural response), and a temporal coincidence between their frequencies. These resonances involve a significant noise level, which is why we usually perform a second FFT in the time domain in order to identify the perturbed harmonic.

Like the vibratory model, the acoustic model is commonly assimilated with simplified geometric shapes. Here, the emission surface is treated as a sphere because the length of the machine is relatively similar to the outer diameter of the machine. This geometric model permits an analytical resolution of the mechanical equations and again leads to modal decomposition. The modal sound power ' $\mathrm{W}_{\mathrm{m}}$ ' radiated by the machine is obtained from the amplitude of modal deflection from the vibratory model ' $\mathrm{Y}_{\mathrm{m}}$ ' (17).

$$
W_{m}(f)=\sigma_{m}(f) \times \frac{1}{2 m+1} \times \frac{\rho_{\text {air }} c_{\text {air }} \times\left[Y_{m} 2 \pi f\right]^{2}}{2} \times 4 \pi R_{s p}
$$

With the characteristics of the environment denoted ' $\rho_{\text {air }}$ ' for the air density and ' $c_{\text {air }}$ ' for the speed of sound in air. ' $\mathrm{R}_{\mathrm{sp}}$ ' is the radius of the equivalent sphere and ' $\sigma_{\mathrm{m}}$ ' the sphere expression of modal radiation efficiency.

The sound power level ' $\mathrm{L}_{\mathrm{W}}$ ' is finally obtained by equation (18), with ' $\mathrm{W}_{0}$ ' being the value corresponding to the beginning of human perception: ' $10^{-12} \mathrm{~W}$ '.

$$
L_{W}=10 \log \left(\sum_{m} W_{m}(f) / W_{0}\right)
$$

Several simulation results and validations of the approach have been presented in previous publications. In [3], we studied an initial machine operating as a generator with no load for which we checked the cogging torque and flux densities in the air-gap (as a function of space and time) with finite element software, and for which the noise was compared with experimental measurements. In [7], we studied the case of a machine operating under load for which we studied the impact of PWM strategies on electromagnetic noise and compared them with experimental measurements. The global model with the couplings was presented in [3]. The input parameters for different models are geometric, electrical, the material characteristics and PWM strategies. The output variables are: noise $\left(\mathrm{L}_{\mathrm{W}}\right)$, torque $\left(\Gamma_{\mathrm{em}}\right)$ and local temperatures $(\mathrm{T})$, as well as mass $(\mathrm{M})$, cost $(€)$, and efficiency $(\eta)$.

\section{OPTIMIZATION}

We developed fast multi-physics models that offer a good compromise between accuracy and computing time. In order to size our machine for traction applications, the models were coupled with an optimization tool [8].

Particle Swarm Optimization (PSO) is used for the optimization of the developed multi-physics models. PSO is a population-based stochastic algorithm which has proven effective in dealing with multi-objective, 
discontinuous problems [9], [10]. The algorithm uses the combined experience of a series of individuals that navigate the research domain in search of optimal regions. Each particle is typically described in the objective space by two vectors (9): its position ' $\mathrm{x}_{\mathrm{i}+1}$ ' and its speed ' $\mathrm{v}_{\mathrm{i}+1}$ '.

$$
\left\{\begin{array}{l}
\vec{v}_{i+1}=\left\{C_{1} \vec{v}_{i}\right\}+\left\{C_{2} \vec{U}_{(0,1)} \otimes\left(\vec{x}_{g}+\vec{x}_{i}\right)\right\}+\left\{C_{3} \vec{U}_{(0,1)} \otimes\left(\vec{x}_{p}+\vec{x}_{i}\right)\right\} \\
\vec{x}_{i+1}=\vec{x}_{i}+\vec{v}_{i+1}
\end{array}\right.
$$

Where ' $\mathrm{x}_{\mathrm{i}}$ ' and ' $\mathrm{v}_{\mathrm{i}}$ ' are the vectors for the previous position and speed respectively. The coefficient ' $\mathrm{C}_{1}$ ' is the inertia weight, which limits the speed of the particles in order to keep them inside the variable space, whereas ' $\mathrm{C}_{2}$ ' and ' $\mathrm{C}_{3}$ ' are "throttle" factors (typically set between 0.4 and 2.05). The vector ' $\mathrm{U}_{(0,1)}$ ' consists of randomly distributed values between ' 0 ' and ' 1 ', that offers the stochastic character of the algorithm. At each iteration the particle moves according to its previous speed, its best solution found so far ' $x_{\mathrm{p}}$ ' and the best solution obtained by the entire swarm ' $\mathrm{x}_{\mathrm{g}}$ ' (Fig.3). The operator ' $\otimes$ ' represents the tensor product.

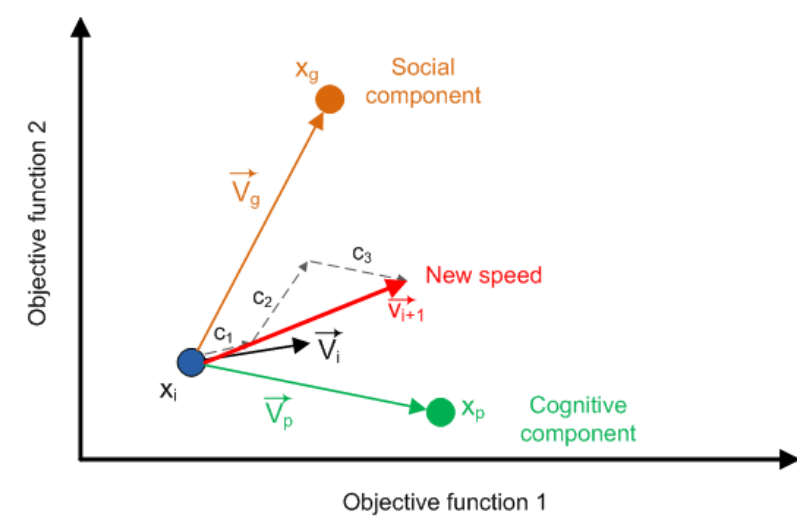

Figure 3. Functioning of Particle Swam Optimization

Although originally the algorithm was developed for mono-objective problems, subsequent multiobjective implementations [11] have showed it to be a real competitor to other well established stochastic algorithms (like GA or simulated annealing) for some types of discontinuous electromagnetic problems. The convergence speed is a key factor in the selection of the algorithm, the number of model evaluations being of great importance on the overall computation time.

A dominance-based multi-objective strategy has been implemented that uses a crowding distance method for maintaining the diversity of the Pareto front [12]. The method is further improved by dividing the population into two sub-swarms based on their fineness evaluation. The best performing individuals will keep a greater influence of their previous personal experience in the following iterations, while the most dominated ones will be more influenced by the global best position (Fig.4a). The contribution of the two components for each sub-swarm is regulated using the two throttle coefficients $\left({ }^{\prime} \mathrm{C}_{2}\right.$ ' and ' $\mathrm{C}_{3}$ '). Each sub-swarm produces its own Pareto front. In order to avoid being trapped in local optima regions, the two resulting fronts are recombined every ten iterations and a new division of the swarm is done based on the new computed fineness values.

In each sub-swarm, the individuals will first be guided towards the extremes of the front and then towards the most isolated individuals in the front (Fig.4b). This insures a good extension of the front and in a second phase a good distribution of the solutions. This sub-swarm MOPSO (Multi-Objective Particle Swam Optimization) implementation has been validated on a number of different design problems [13]. 


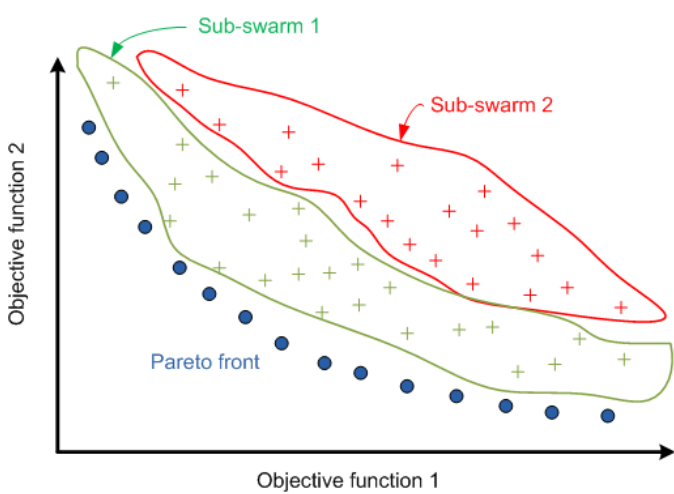

a/ Enhancement by dividing the population into two sub-swarms

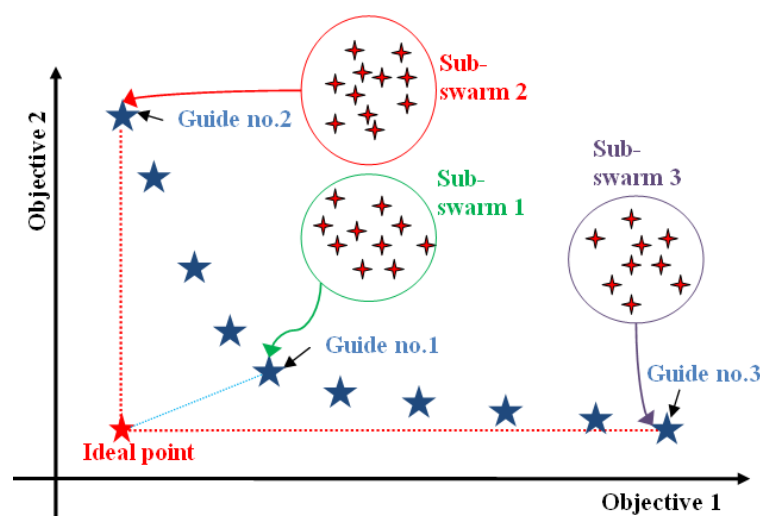

b/ Sub-swarm strategy for the extension of the front and the distribution of the solutions

Figure 4. Multi-Objective Particle Swam Optimization

The objective functions of the optimization problem are the average torque and electromagnetic noise, while torque ripple, weight and price are considered as constraints. Ripple torque is expressed as a percentage of average torque. The input parameters are all geometric: slot and magnet openings $\left(\alpha_{\mathrm{s}}, \alpha_{\mathrm{m}}\right)$, as well as stator yoke, air-gap and magnet heights $\left(h_{\mathrm{ys}}, \mathrm{h}_{\mathrm{g}}, \mathrm{h}_{\mathrm{m}}\right)$. These parameters do not influence the global volume which is kept constant throughout the process. The size of rotor yoke is changed in order to keep the volume constant.

In Fig.5 five Pareto fronts are presented for speeds ranging from 2000rpm to 5000rpm, under load. It can be seen that there is no obvious correlation between ripple torque and electromagnetic noise in the machine as described in [14], although some works show that a reduction of ripple and cogging torque can significantly reduce the electromagnetic noise radiated by the machine [15]. At $2000 \mathrm{rpm}$ the ripple torque has the maximum values for low noise, and it also depends on the machine speed.

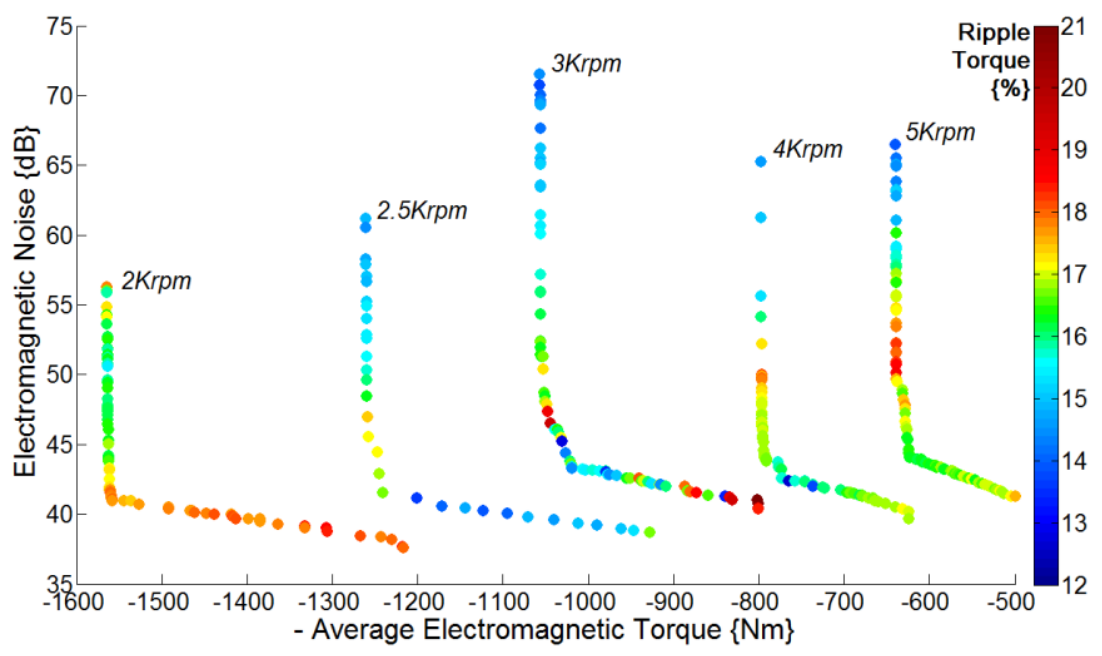

Figure 5. Compromise between average torque and electromagnetic noise versus ripple torque $(\%)$ for different speeds

For the same Pareto fronts, the variations of input variables according to the initial point on the Pareto front are described: slot opening $\left(\alpha_{\mathrm{s}}= \pm 20 \%\right)$, magnet opening $\left(\alpha_{\mathrm{m}}= \pm 16.7 \%\right)$, magnet height $\left(\mathrm{h}_{\mathrm{m}}= \pm 20 \%\right)$, air-gap height $\left(\mathrm{h}_{\mathrm{g}}= \pm 10 \%\right)$ and stator yoke height $\left(\mathrm{h}_{\mathrm{ys}}= \pm 25 \%\right)$.

At different speeds, some trends can be completely different: for example, at some speeds the machine is close to the resonance frequencies which can cause other problems. To solve this problem in the design phase, we can apply a weighted mean linked to several operating points. For example, a car with a different profile (city, highway, etc.) with $40 \%$ at $5000 \mathrm{rpm}, 30 \%$ at $3000 \mathrm{rpm}$, and $30 \%$ for the other speeds. For the end of the study, we will consider only the changes in input variables for a speed of $5 \mathrm{Krpm}$, close to the rated speed. 
Fig.6a shows the influence of the stator yoke height. An increase of the height of the stator yoke can change the main resonance frequency and reduce the electromagnetic noise for this speed. In our case, the main resonance frequency is for mode zero [3]. By contrast, decreasing it involves higher torque and is linked to the variation of the height of the rotor yoke.

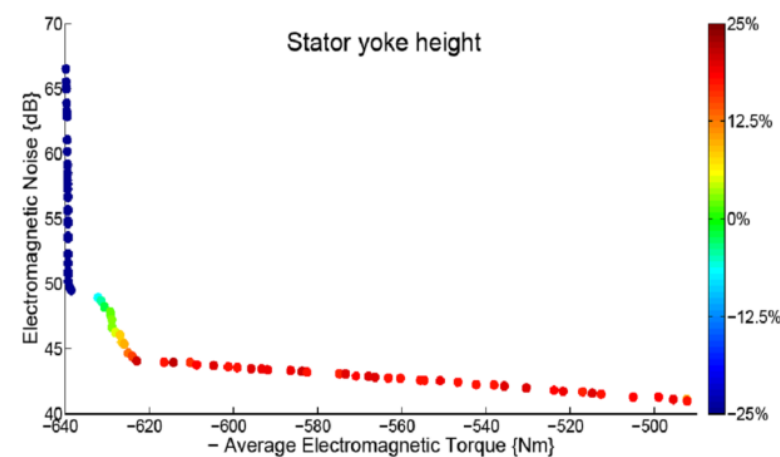

a/ versus input variable stator yoke

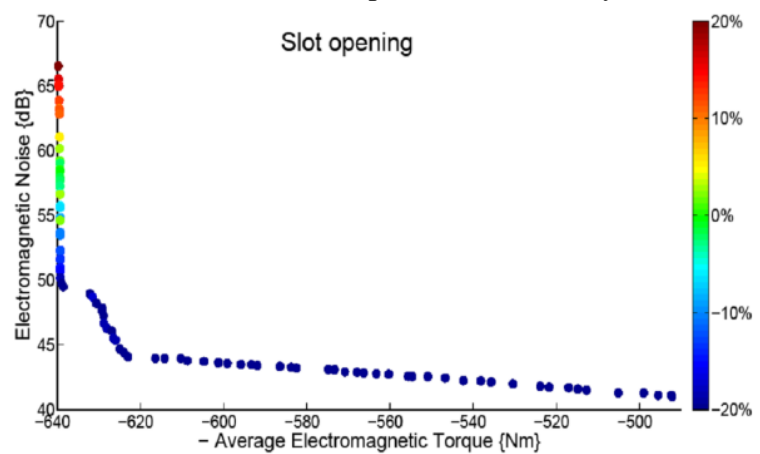

c/ versus input variable magnet opening

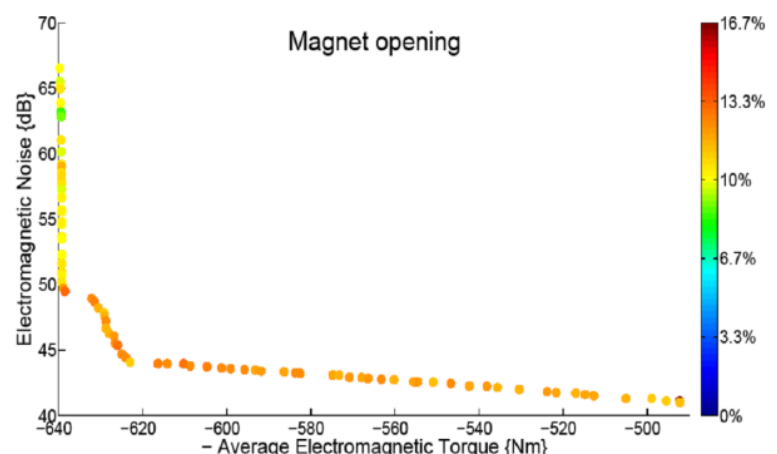

b/ versus input variable slot openings

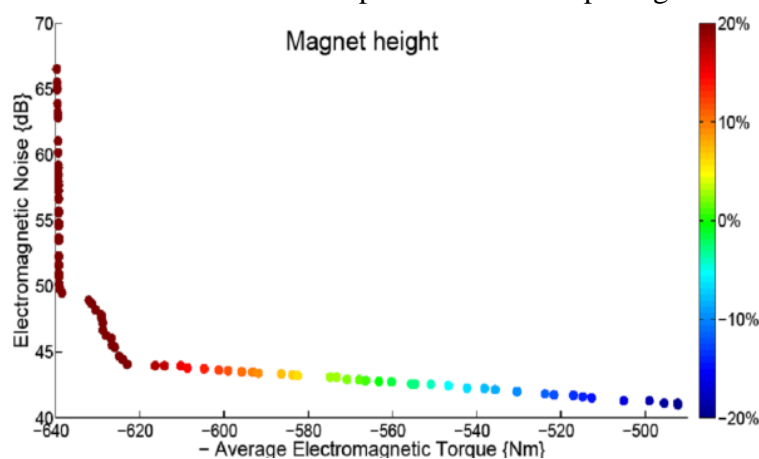

$\mathrm{d} /$ versus input variable magnet height

Figure 6. Compromise between average torque and electromagnetic noise

For the magnet opening, we observe that the entire range of variation is not used (Fig.6b) as it increases only by $10 \%$ and $12 \%$. Increasing the magnet opening maximizes the flux in the magnetic circuit and thus maximizes the electromagnetic torque. If this parameter increases, the saturation phenomenon leads to leakages in the magnetic circuit and reduces electromagnetic performance.

For the slot opening and the magnet height, the origin of electromagnetic noise is mainly due to the harmonics of the slotting permeance field coupled with the magnet field. Increasing the width of the slot thus increases the noise (Fig.6c). PMSM (Fig.6d).

Positioning the magnet higher in the magnetization direction affects only the average torque of the

In addition, a sensitivity study (SES) was performed to validate the robustness of the design technique, in order to check the design chosen when subjected to manufacturing constraints. In this process it was necessary to consider a tolerance on the dimensions of the machine. The aim was to select different points on the Pareto front and to associate them with the sensitivity analysis.

Here, we chose an optimal point at $4500 \mathrm{rpm}$. For this point, the input variables were made to fluctuate around $\pm 5 \%$ in order to check the robustness on the two objective functions. We defined a full factorial design with three levels and five factors and performed " 243 " $\left(3^{5}\right)$ experiments for each solution. 

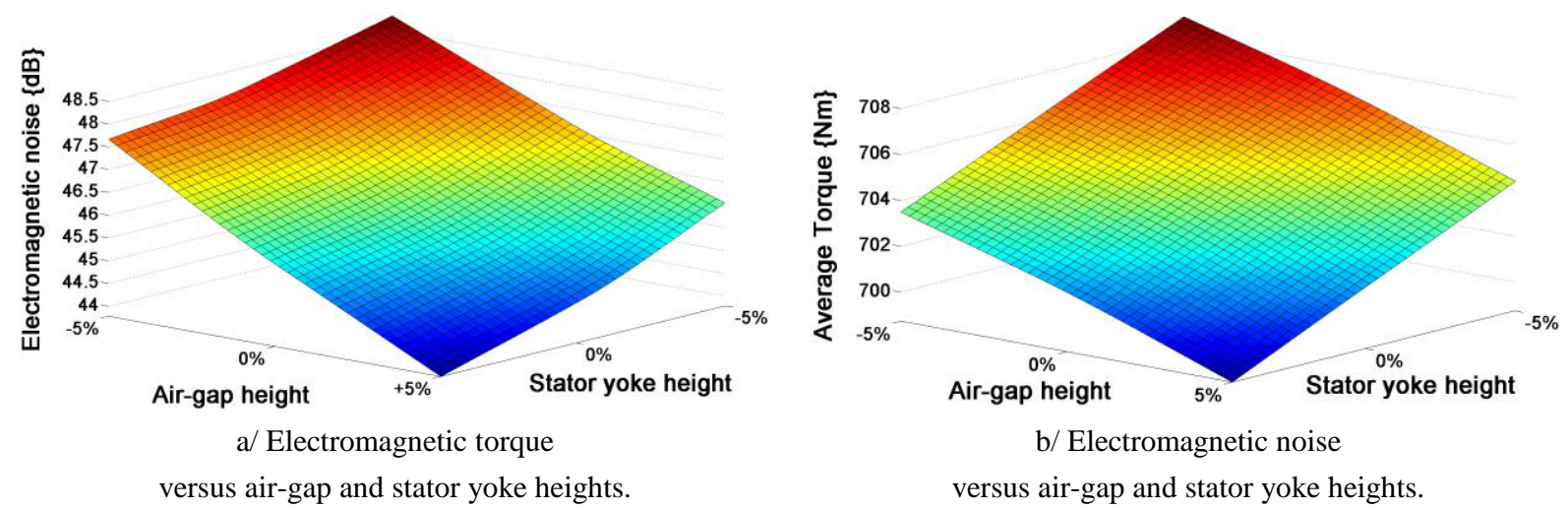

b/ Electromagnetic noise

versus air-gap and stator yoke heights.

Figure 7. Sensitivity studies

In Fig.7a and Fig.7b, show the influence of the variation of the air-gap and the stator yoke lengths on the objective functions. It should be noted that these trends are true at local level and cannot be generalized. In this range of variation, increasing the air-gap and the stator yoke reduces the electromagnetic noise of the machine but also decreases the average torque. It can be seen from this example that the trends are clearly in opposition.

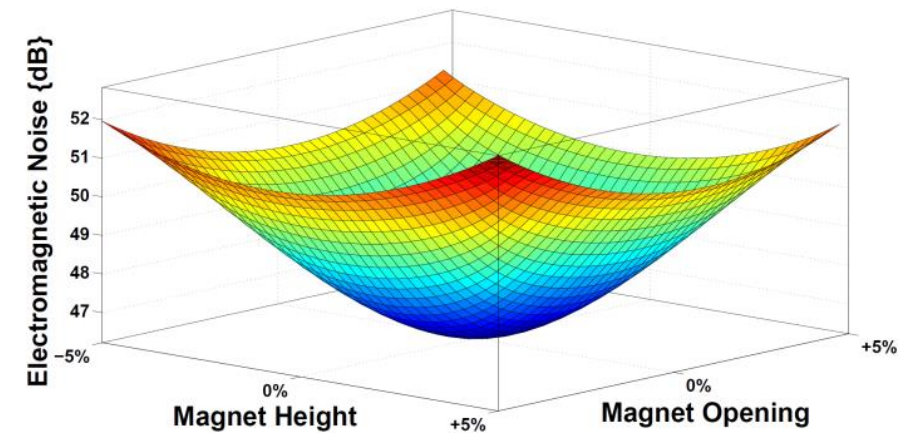

Figure 8. Sensitivity studies: Electromagnetic noise versus magnet length and magnet opening

Fig. 8 shows the importance of the dimensions of the magnet with regard to the noise. It can also be seen that an optimum in the design of the magnet is reached. Any deviation from the initial value increases the noise level of the machine. The maximum increase observed here is higher than $+6 \mathrm{~dB}$. It corresponds to four times the noise radiated by the machine.

\section{CONCLUSION}

A multi-physics model was built using lumped models to take into account complex geometries and local phenomena (local saturation, eddy currents, demagnetization, etc.). Compared to finite element models, the lumped models allow easy coupling between multi-physics models and non-scientific models such as environmental, cost, etc. In addition, the most important advantage is its shorter computation time, especially in the case of a coupled multi-physics design process.

The multi-objective optimization was performed using PSO, an algorithm that ensures quick and accurate convergence towards optimal solutions. The optimization process offers different geometric configurations of the machine that best satisfy the objectives while considering the constraints imposed.

We focused on the design rules of a permanent magnet synchronous machine and in particular on the electromagnetic torque and electromagnetic noise. Several geometric dimensions were modified in order to find the best compromise between average torque and electromagnetic noise. We observed that there is no obvious correlation between ripple torque and noise. We verified the trends when varying the variation of input parameters for a given speed. Finally, we performed a sensitivity study to test the robustness of an optimum solution. 


\section{REFERENCES}

[1] Huang, S.; Aydin, M.; Lipo, T.A., "Electromagnetic vibration and noise assessment for surface mounted PM machines," Power Engineering Society Summer Meeting, 2001, vol.3, no., pp.1417,1426 vol.3, 2001

[2] J.F.Gieras, C.Wang, and J.C.Lao, "Noise of Polyphase Electric Motors", Boca Raton, FL: Taylor \& Francis, 2006.

[3] Bracikowski, N.; Hecquet, M.; Brochet, P.; Shirinskii, S.V., "Multiphysics Modeling of a Permanent Magnet Synchronous Machine by Using Lumped Models," Industrial Electronics, IEEE Transactions on , vol.59, no.6, pp.2426,2437, June 2012

[4] H. Roisse, M. Hecquet, and P. Brochet, "Simulations of synchronous machines using an electric-magnetic coupled network model", Magnetics, IEEE Transactions on, vol. 34, no. 5, pp. 3656 -3659, 09-1998.

[5] Alberti, L.; Bianchi, N.; "A Coupled Thermal-Electromagnetic Analysis for a Rapid and Accurate Prediction of IM Performance," Industrial Electronics, IEEE Transactions on, vol.55, no.10, pp.3575-3582, Oct. 2008.

[6] Fiedler, J.O.; De Doncker, R.W., "Simplified calculation of radial force spectrum in SMR for acoustic noise prediction in preliminary machine design," Power Electronics, Machines and Drives, 2006. PEMD 2006. The 3rd IET International Conference on , vol., no., pp.652,656, 4-6 April 2006

[7] Bracikowski, N.; Fakam, M.; Hecquet, M.; Brochet, P.; Lanfranchi, V., "Characterisation of radial vibration force and electromagnetic noise behaviour of a PWM-fed permanent magnet synchronous machine," Electrical Machines (ICEM), 2012 XXth International Conference on , vol., no., pp.2936,2942, 2-5 Sept. 2012.

[8] R. Ben-Ayed, A. Berbecea, S. Brisset, F. Gillon, P. Brochet, "Comparison between Efficient Global Optimization and Output Space Mapping Technique", International Journal of Applied Electromagnetics and Mechanics, vol 37, pp 109-120, 2011.

[9] L.S. Coelho and H.V.H., Alotto,P. Ayala, "A multi-objective gaussian particle swarm approach applied to electromagnetic optimization," IEEE Trans. on Magnetics, vol. 46, no. 8, pp. 3289-3292, August 2010.

[10] J-H Seo, C-H Im, S-Y Kwak, C-G Lee, and H-K Jung, "An improved particle swarm optimization algorithm mimicking territorial dispute between groups for multimodal function optimization problems ," IEEE Trans. on Magnetics, vol. 44, no. 6, pp. 1046-1049, June 2008.

[11] U Baumgartner, Ch. Magele, and W Renhart, "Pareto Optimality and Particle Swarm Optimization," IEEE Trans. on Magnetics, vol. 40, no. 2, pp. 1172-1175, March 2004.

[12] C.R. Raquel, P.C. Jr Naval, "An effective use of crowding distance in multiobjective particle swarm optimization," in Proc.of Genetic and Evolutionary Computation Conference, Washington DC, 2005, pp.257-264.

[13] D. Ilea, A. Berbecea, F. Gillon, P. Brochet and M.M. Radulescu, "Multi-objective PSO tool for electromagnetic problems with grid computing", International Conference on the Computation of Electromagnetic Fields, COMPUMAG 2011, Sydney, Australia, 07-2011

[14] Islam, R.; Husain, I.; "Analytical Model for Predicting Noise and Vibration in Permanent-Magnet Synchronous Motors," IEEE Transactions on Industry Applications, vol.46, no.6, pp.2346-2354, Nov.-Dec. 2010.

[15] S. M. Hwang, D. K. Lieu, "Reduction of torque ripple in brushless DC motors," IEEE Trans. Magn., vol. 31, no. 6, pp. 3737-3739, sep. 1995. 